Pregledni znanstveni članek / Review article

\title{
Prednosti in slabosti različnih protokolov vodenja vrednosti glukoze v krvi pri kritično bolnih pacientih: pregled literature
}

\author{
The benefits and weaknesses of various blood glucose control protocols in critically \\ ill patients: literature review
}

Sedina Kalender Smajlović

\begin{abstract}
IZVLEČEK
Ključne besede: hiperglikemija; koncentracija glukoze v krvi; inzulinska infuzijska mešanica

Key words: hyperglycemia; blood glucose concentration; continuous insulin infusion

pred. Sedina Kalender Smajlović, dipl. m. s., mag. zdr. neg.; Fakulteta za zdravstvo Angele Boškin, Spodnji Plavž 3 4270 Jesenice, Slovenija

Kontaktni e-naslov / Correspondence e-mail: skalendersmajlovic@fzab.si

Uvod: Medicinske sestre v enotah intenzivne terapije uravnavajo ciljno vrednost glukoze v krvi pri kritično bolnih po sprejetih in veljavnih protokolih. Namen raziskave je bil raziskati prednosti in slabosti različnih protokolov vodenja vrednosti glukoze v krvi pri kritično bolnih.

Metode: Uporabljen je bil sistematični pregled znanstvene in strokovne literature. Iskanje literature je potekalo od 1.2. 2017 do 8. 8. 2017. V pregled so bile vključene naslednje baze: COBIB.SI, Digitalna knjižnica Slovenije - Dlib.si, CINAHL, ProQuest, PubMed in Google Učenjak. Iskanje je potekalo z različnimi kombinacijami ključnih besed v slovenskem in angleškem jeziku: prednosti, slabosti, medicinske sestre, kritično bolni, glukoza $v$ krvi in protokoli za vodenje vrednosti glukoze $v$ krvi. Uporabljen je bil Boolov operater AND. Iz iskalnega nabora 1064 zadetkov je bilo v končno analizo vključenih 15 člankov. Za obdelavo podatkov je bil uporabljen model analize konceptov.

Rezultati: Identificirana so bila tri tematska področja: (1) primernost različnih protokolov za vodenje vrednosti glukoze v krvi, (2) delovne obremenitve medicinskih sester pri teh protokolih in (3) varnost protokolov. Prednosti računalniško podprtega protokola za vodenje vrednosti glukoze v krvi so v boljšem doseganju ciljne vrednosti koncentracije glukoze $\mathrm{v}$ krvi, slabosti pa v pojavu odstopanj v zvezi z načrtovanim časom za merjenje glukoze v krvi.

Diskusija in zaključek: Nekatere raziskave ugotavljajo prednosti računalniško podprtih protokolov za vodenje vrednosti glukoze v krvi v smislu tehnoloških izboljšav, zmanjšanja delovnih obremenitev medicinskih sester in izboljšanja varnosti pacientov. Raziskava prispeva $\mathrm{k}$ izboljševanju klinične prakse pri delu $\mathrm{s}$ kritično bolnimi pacienti.
\end{abstract}

Članek je nastal v okviru doktorskega študija na Medicinski fakulteti Univerze v Ljubljani pri predmetu Na dokazih podprto delo $v$ zdravstveni negi in zdravstvu.

\footnotetext{
ABSTRACT

Introduction: Critical care nurses adjust the blood glucose target in critically ill according to the accepted and validated blood glucose control protocols. The purpose of this research was to investigate the benefits and weaknesses of blood glucose control protocols in critically ill patients.

Methods: A systematic review of the scientific and professional literature was conducted. The research was done from 1 February 2017 to 8 August 2017. Databases COBIB.SI, The Digital Library of Slovenia - dLib.si, CINAHL, ProQuest, PubMed and Google Scholar were used for the literature review and analysis. The search was performed with the following key words in the Slovene and English language: benefits, weaknesses, critical care nurses, critically ill, blood glucose and protocols for tight glycemic control. The Boolean AND operator was used. From the total of 1064 results, 15 articles were included in the detailed analysis. The concept analysis model was used to process data.

Results: Three thematic areas have been identified: (1) the suitability of different protocols for the management of blood glucose levels, (2) nurses' workload while following these protocols, and (3) the safety of the blood glucose control protocols. The benefits of a computerized blood glucose control protocol lie in better achievement of the target blood glucose concentration. The disadvantages of blood glucose control through control protocols are deviations related to the time allocated to blood glucose measurement.

Discussion and conclusion: Some research has established benefits of computerized blood glucose control protocols in terms of technological improvements, reducing the nurses' workload and the safety of blood glucose control protocols. The research makes a contribution to improving the clinical practice in working with critically ill patients.
} 


\section{Uvod}

Pri kritično bolnih se $\mathrm{v}$ času zdravljenja $\mathrm{v}$ enoti intenzivne terapije pogosto pojavi hiperglikemija, ki jo lahko povzročijo različni dejavniki. Vzrok za hiperglikemijo je npr. močen fiziološki stres, ki vodi do sprememb $\mathrm{v}$ ravni hormonov, pa tudi nepravilna prehrana, jemanje nekaterih zdravil in nezadostna proizvodnja inzulina (Hsu, 2012). Pri kritično bolnih pacientih se pri ciljnem uravnavanju vrednosti glukoze v krvi lahko pojavijo številni zapleti, med pogostejšimi je hiperglikemija (The Nice Sugar Investigators, 2012). Kopecky in sodelavci (2013) govorijo o t. i. stresni hiperglikemiji, ki se pojavi pri $90 \%$ kritično bolnih, kar posledično lahko vodi v povečano morbidnost oz. tveganje za smrt. Farrokhi in sodelavci (2011) navajajo, da je hiperglikemija prisotna pri $40 \%$ kritično bolnih pacientov in pri $80 \%$ pacientov po operaciji srca.

Chang in sodelavci (2012) navajajo, da skrb za kritično bolne paciente zahteva natančno opazovanje fizioloških znakov, zato je uporaba različnih protokolov zdravstvene oskrbe kritično bolnih pacientov postala bolj pogosta. Vodenje vrednosti glukoze v krvi pri kritično bolnih pacientih $\mathrm{s}$ pomočjo protokolov zdravnikom in medicinskim sestram predstavlja strokovni izziv (Holzinger, et al., 2008). Dharmalingam (2016) navaja, da optimalna vrednost koncentracije glukoze v krvi pri kritično bolnih pacientih še ni točno določena in da je še vedno predmet številnih razprav. Tudi Farrokhi in sodelavci (2011) navajajo, da je bila raziskava Van den Bergha in sodelavcev, leta 2001 izvedena na vzorcu 1548 mehansko ventiliranih kritično bolnih v kirurških intenzivnih terapijah, prva prospektivna randomizirana kontrolirana klinična raziskava, ki je uvedla vodenje koncentracije glukoze v krvi s pomočjo protokolov. Desetletje mlajša raziskava NICE-SUGAR je ugotovila sporno stanje, in sicer, da zelo strogo vodenje vrednosti glukoze $\mathrm{v}$ krvi po protokolu lahko kritično bolnim pacientom škodi (The Nice Sugar Investigators, 2012). Al-Tarifi in sodelavci (2011) na osnovi kohortne raziskave na vzorcu 523 kritično bolnih pacientov navajajo, da optimalna raven glukoze v krvi znaša $8,1 \mathrm{mmol} / \mathrm{l}(166 \mathrm{mg} / \mathrm{dl})$. Po drugi strani Krinsley (2015) na osnovi pregleda literature ugotavlja, da pri kritično bolnih pacientih ne moremo določiti optimalne vrednosti glukoze $\mathrm{v}$ krvi, saj predpisana koncentracija glukoze $\mathrm{v}$ krvi ne more biti ustrezna vsem kritično bolnim pacientom. Gardner (2014) navaja, da klinična praksa $\mathrm{v}$ protokolih vodenja vrednosti glukoze v krvi pri kritično bolnih pacientih za ciljne vrednosti postavlja območje $4,4-6,1 \mathrm{mmol} / \mathrm{l} \mathrm{z}$ namenom izogniti se morebitnim škodljivim učinkom hiperglikemije.

DuBose in sodelavci (2009) preko izvedene prospektivne raziskave $\mathrm{v}$ travmatološki intenzivni terapiji zaključujejo, da pomen vodenja vrednosti glukoze $\mathrm{v}$ krvi po protokolih sodi med rutinske aktivnosti $\mathrm{v}$ zdravstveni negi ter da vključenost medicinskih sester in povečanje njihove odgovornosti izboljšuje varnost in učinkovitost omenjenih protokolov. Nelson (2011) navaja, da je nadzor nad nivojem glukoze $\mathrm{v}$ krvi namenjen vzdrževanju ciljnih glikemičnih vrednosti, kar medicinske sestre $\mathrm{v}$ intenzivni terapiji dosežejo $\mathrm{z}$ rednim spremljanjem koncentracije glukoze $\mathrm{v}$ krvi in titracijo inzulinske infuzijske mešanice $\mathrm{v}$ želenih razponih, ki so določeni s protokolom. Sauer in Van Horn (2009) navajata, da so za izvajanje protokolov vodenja vrednosti glukoze v krvi pri kritično bolnih pacientih odgovorne medicinske sestre, zaposlene $\mathrm{v}$ enotah intenzivne terapije, pri čemer s strani zdravnikov dobijo le minimalna dodatna navodila. Schultz in sodelavci (2012) na osnovi pregleda literature (pregled ekspertnih mnenj, kliničnih poročil) navajajo, da medicinske sestre lahko $s$ pomočjo ustreznih protokolov primerno in varno vodijo vrednosti glukoze $\mathrm{v}$ krvi pri kritično bolnih pacientih.

Beliard in sodelavci (2016) na osnovi izvedene presečne raziskave navajajo, da imata pri zagotavljanju skrbi za paciente pomembno vlogo znanje in percepcija o zagotavljanju optimalne zdravstvene oskrbe. Nadalje navajajo, da je na področju vodenja vrednosti glukoze v krvi s pomočjo protokolov potreben razvoj izobraževalnih programov. Sauer in Van Horn (2009) navajata, da je praksa vodenja vrednosti glukoze v krvi pri kritično bolnih pacientih s pomočjo protokolov sprejeta $\mathrm{v}$ številnih kliničnih okoljih. Poudarjata, da čeprav so protokoli vodenja vrednosti koncentracije glukoze v krvi jasno dokumentirani, lahko zaradi možnosti pojava hipoglikemije predstavljajo potencialno tveganje za varnost kritično bolnih pacientov. Poudarjata tudi, da protokoli vodenja vrednosti koncentracije glukoze $\mathrm{v}$ krvi povečujejo obseg delovnih obremenitev medicinskih sester.

\section{Namen in cilji}

Namen raziskave je bil ugotoviti prednosti in slabosti najbolj pogostih protokolov vodenja glukoze v krvi pri kritično bolnih pacientih. Cilj raziskave je bil preko sistematičnega pregleda literature prikazati najbolj pogoste protokole vodenja vrednosti glukoze $\mathrm{v}$ krvi ter tako prispevati k nekaterim novostim na področju vodenja vrednosti glukoze v krvi pri kritično bolnih pacientih. Raziskovalno vprašanje je bilo:

- Kakšne so prednosti in slabosti različnih protokolov vodenja vrednosti glukoze $\mathrm{v}$ krvi pri kritično bolnih pacientih in kakšne so ugotovitve raziskav $s$ tega področja?

\section{Metode}

Sistematični pregled literature temelji na analizi raziskav, ki so obravnavale prednosti in slabosti vodenja vrednosti glukoze $\mathrm{v}$ krvi $\mathrm{v}$ povezavi $\mathrm{z}$ medicinskimi sestrami in različne protokole vodenja 
Tabela 1: Vključitveni in izključitveni kriteriji

Table 1: Inclusion and exclusion criteria

\begin{tabular}{ll}
\hline Vključitveni kriteriji / Inclusion criteria & Izključitveni $k$ riteriji / Exclusion criteria \\
\hline Besedilo v slovenskem ali angleškem jeziku & Članek, ki ni napisan v slovenskem ali angleškem jeziku \\
\hline Dostopnost celotnega besedila ali povzetka & Dostopnost le bibliografskih podatkov o članku \\
\hline Tematska ustreznost & Izbrana tematika ni neposredno obravnavana \\
\hline Obravnavani vzorec so kritično bolni odrasli & Obravnavani vzorec so kritično bolni otroci \\
\hline Raziskovalni članek ali pregledni znanstveni članek & Poljudni prispevek, kratko poročilo, opis primera \\
\hline Recenzirano besedilo & Nerecenzirano besedilo \\
\hline Objava v letih 2006-2017 & Objava pred letom 2006 \\
\hline
\end{tabular}

vrednosti glukoze $\mathrm{v}$ krvi. Uporabili smo pristop, ki ga opisujejo Cronin in sodelavci (2008). Pristop vključuje oblikovanje raziskovalnega vprašanja, določanje meril za vključitvene in izključitvene kriterije izbora primerne literature, oceno kakovosti vključene literature, analizo, sintezo in diseminacijo ključnih ugotovitev. S pregledom literature smo predstavili ugotovitve raziskav, ki navajajo prednosti in slabosti pri vodenju vrednosti glukoze v krvi s pomočjo protokolov, kjer pri izvedbi le-teh sodelujejo medicinske sestre $\mathrm{v}$ enotah intenzivne terapije.

\section{Metode pregleda}

Izvedli smo sistematični pregled literature. Uporabljena je bila deskriptivna raziskovalna metoda s pregledom domače in tuje strokovne in znanstvene literature, indeksirane $\mathrm{v}$ mednarodnih bazah podatkov. Najprej smo iskali literaturo, objavljeno v slovenskem jeziku, in sicer s pomočjo vzajemne bibliografsko-kataložne baze podatkov slovenskih knjižnic COBIB.SI ter Digitalne knjižnice Slovenije - Dlib.si. Uporabili smo naslednje ključne besede: prednosti, slabosti, medicinske sestre, kritično bolni, glukoza $v$ krvi in protokoli za vodenje vrednosti glukoze v krvi. Različne kombinacije teh ključnih besed so v slovenskih bazah podale zadetke, ki so se nanašali predvsem na kritično bolne otroke, kar pa ni bil predmet naše raziskave, zato zadetkov $\mathrm{v}$ slovenskem jeziku $\mathrm{v}$ končni pregled nismo vključili. Literaturo, objavljeno $\mathrm{v}$ angleškem jeziku, smo iskali v naslednjih mednarodnih bazah podatkov: CINAHL, ProQuest, PubMed in Google Učenjak. Uporabili smo naslednje ključne besedne zveze, povezane $\mathrm{z}$ Boolovim operaterjem AND (slovensko IN): benefits, weaknesses, critical care nurses, critically ill, blood glucose, protocols for tight glycemic control. Za določanje hierarhije dokazov $\mathrm{v}$ znanstvenoraziskovalnem delu smo uporabili vir Polit in Beck (2008). Vključitveni in izključitveni kriteriji so prikazani v Tabeli 1 . Pri vključitvenih kriterijih smo upoštevali, da so bili članki objavljeni v slovenskem ali angleškem jeziku, da so bili dostopni v celotnem besedilu ali kot povzetki in tematsko ustrezni. Za vključitvene kriterije smo tudi upoštevali, da so bili $\mathrm{v}$ člankih obravnavani odrasli kritično bolni, da so članki bili recenzirani, kategorizirani kot raziskovalni ali pregledni znanstveni članek in objavljeni v časovnem obdobju 2006-2017. Iskanje literature je potekalo od 1.2. 2017 do 8. 8. 2017.

\section{Rezultati pregleda}

Specifikacija iskalnih besed in različne kombinacije ključnih iskalnih besed in besednih zvez z Boolovim operaterjem AND (slovensko IN) je podala širši nabor relevantne literature. Pregledali smo naslove in izvlečke raziskav ter identificirali dvojnike. Strategija iskanja $\mathrm{v}$ podatkovnih bazah je skupaj podala 1064 zadetkov v angleškem jeziku. T. i. sive literature nismo vključili, saj je nismo uspeli pridobiti. Po odstranitvi duplikatov je začetna merila za vključitev v raziskavo izpolnjevalo 1052 zadetkov. Po pregledu naslovov, izvlečkov in drugih podatkov o objavi smo na prvem situ izključili 888 zadetkov. Po pregledu 164 ustreznih zadetkov smo jih nato 149 izključili zaradi vsebinske neprimernosti. $V$ končno analizo smo tako vključili 15 zadetkov. Potek pridobivanja za našo raziskavo relevantnih člankov je razviden s Slike 1, kjer smo za prikaz pregleda podatkovnih baz in odločanja o uporabnosti pregledanih virov uporabili metodo PRISMA (Preffered Reporting Items for Systematic Review and Meta-Analysis) (Welch, et al., 2012), ki smo jo za namen naše raziskave deloma prilagodili.

\section{Ocena kakovosti pregleda in opis obdelave podatkov}

Pri iskanju literature smo se najprej osredotočili na iskanje po recenziranih znanstvenih revijah in publikacijah. Glede na hierarhijo iskanja dokazov, kot jo opisujeta Polit in Beck (2008), smo glede na definirano raziskovalno vprašanje $\mathrm{v}$ končni analizi uporabili 15 


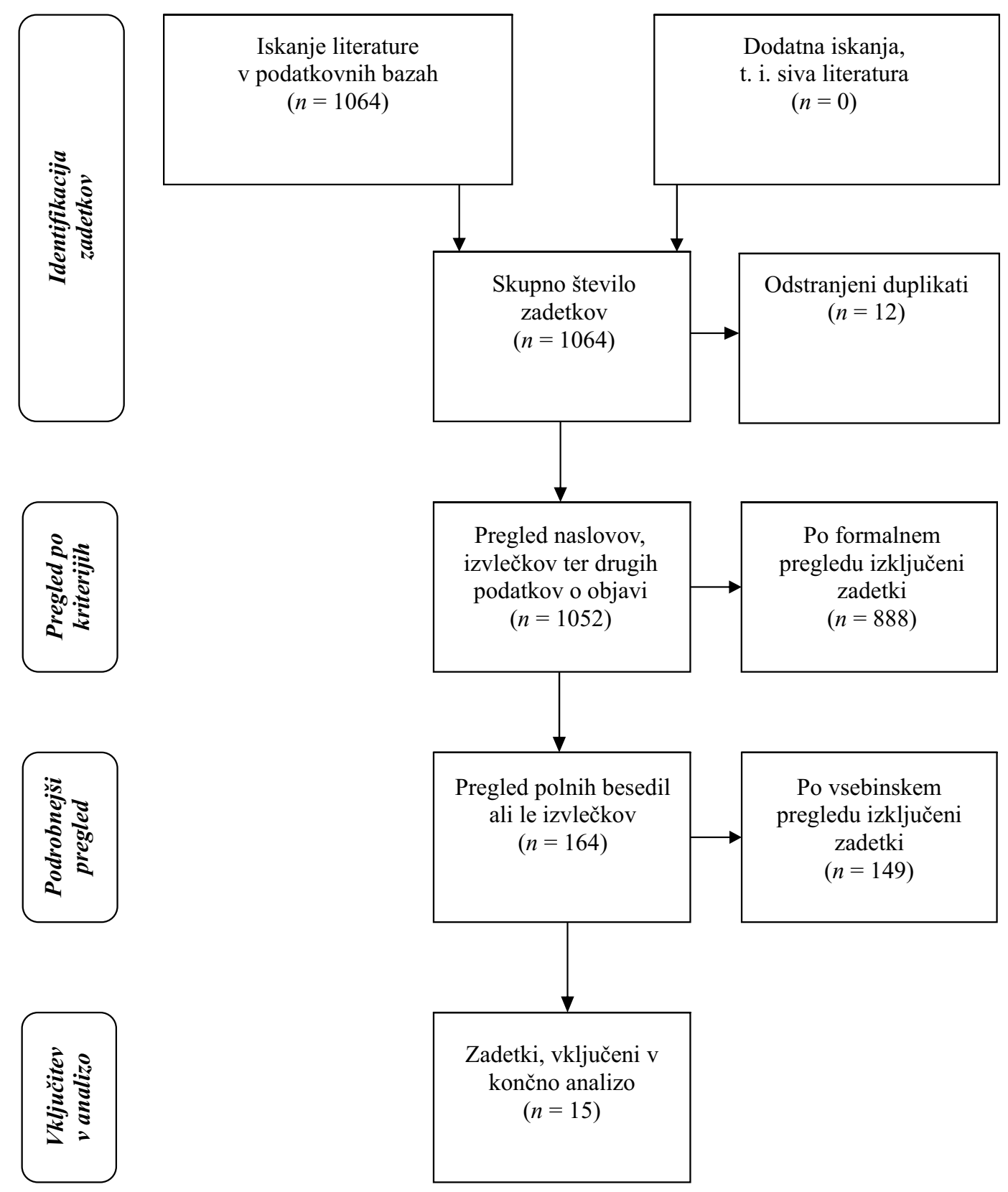

Slika 1: Rezultati pregleda literature po metodologiji PRISMA

Figure 1: Results of literature review based on the PRISMA method

izvirnih znanstvenih člankov, njihovi raziskovalni dizajni so razvidni iz Tabele 2. Med najvišje dokaze, tj. na nivo 1 , avtorja umeščata sistematični pregled literature: $1 \mathrm{a}$ - sistematični pregled randomiziranih kliničnih raziskav; $1 \mathrm{~b} \quad-$ sistematični pregled nerandomiziranih raziskav. $\mathrm{Na}$ nivo 2 umeščata: 2 a - posamezne randomizirane klinične raziskave in $2 \mathrm{~b}$ - posamezne nerandomizirane raziskave. Nižje sledijo: nivo 3 - sistematični pregledi koleracijskih ali opazovalnih raziskav, nivo 4 - posamezne koleracijske ali opazovalne raziskave, nivo 5 - sistematični pregledi opisnih, kvalitativnih ali fizioloških raziskav, nivo 6 posamične opisne, kvalitativne ali fiziološke raziskave in nivo 7 - mnenja avtorjev ali ekspertnih komisij.

\section{Rezultati}

Rezultati so predstavljeni v okviru treh tematskih področij (tabele 2-4), ki smo jih oblikovali na podlagi ugotovitev pregledanih raziskav: (1) primernost različnih protokolov za vodenje vrednosti glukoze $\mathrm{v}$ krvi pri kritično bolnih pacientih (Tabela 2), (2) 
delovne obremenitve medicinskih sester pri različnih protokolih za vodenje vrednosti glukoze $\mathrm{v}$ krvi pri kritično bolnih pacientih (Tabela 3) in (3) varnost različnih protokolov za vodenje vrednosti glukoze $\mathrm{v}$ krvi pri kritično bolnih pacientih (Tabela 4).
Primernost različnih protokolov za vodenje vrednosti
glukoze v krvi pri kritično bolnih pacientih

Preko izvedene randomizirane klinične raziskave so Corrêa in sodelavci (2009) preverjali primernost treh

Tabela 2: Raziskave, vključene v pregled literature v okviru prvega tematskega področja - primernost različnih protokolov vodenja vrednosti glukoze $v$ krvi pri kritično bolnih pacientih

Table 2: The studies included in the literature review within the framework of the first thematic area - suitability of various blood glucose protocols in critically ill patients

\begin{tabular}{|c|c|c|c|c|c|}
\hline $\begin{array}{l}\text { Avtor in leto / } \\
\text { Author and } \\
\text { year }\end{array}$ & $\begin{array}{l}\text { Namen / } \\
\text { Aim }\end{array}$ & $\begin{array}{l}\text { Raziskovalni } \\
\text { dizajn / } \\
\text { Research design }\end{array}$ & $\begin{array}{l}\text { Zbiranje in analiza } \\
\text { podatkov / } \\
\text { Data collection } \\
\text { and analysis }\end{array}$ & $\begin{array}{l}\text { Lastnosti } \\
\text { vzorca / } \\
\text { Sample } \\
\text { characteristics }\end{array}$ & $\begin{array}{l}\text { Ključne ugotovitve / } \\
\text { Key findings }\end{array}$ \\
\hline $\begin{array}{l}\text { Corrêa, et al., } \\
2009\end{array}$ & $\begin{array}{l}\text { Oceniti percepcijo } \\
\text { treh različnih } \\
\text { protokolov s strani } \\
\text { medicinskih sester }\end{array}$ & $\begin{array}{l}\text { Randomizirana } \\
\text { kontrolirana } \\
\text { raziskava }\end{array}$ & $\begin{array}{l}\text { Vprašalnik o } \\
\text { ocenjevanju } \\
\text { učinkovitosti, koristi, } \\
\text { varnosti, tveganjih } \\
\text { in izvedljivosti } \\
\text { treh obravnavanih } \\
\text { protokolov }\end{array}$ & $\begin{array}{l}60 \text { medicinskih } \\
\text { sester }\end{array}$ & $\begin{array}{l}57 \% \text { medicinskih } \\
\text { sester je mnenja, da } \\
\text { je najbolj primeren } \\
\text { računalniško podprti } \\
\text { inzulinski protokol. }\end{array}$ \\
\hline $\begin{array}{l}\text { Dumont \& } \\
\text { Bourguignon, } \\
2012\end{array}$ & $\begin{array}{l}\text { Preučiti učinke } \\
\text { uporabe } \\
\text { računalniško } \\
\text { vodenega } \\
\text { protokola pri } \\
\text { odmerjanju } \\
\text { inzulina v } \\
\text { kardioloških } \\
\text { intenzivnih } \\
\text { terapijah }\end{array}$ & $\begin{array}{l}\text { Prospektivna } \\
\text { randomizirana } \\
\text { raziskava }\end{array}$ & $\begin{array}{l}\text { Ocenjevanje } \\
\text { računalniškega in } \\
\text { tradicionalnega } \\
\text { protokola } z \\
\text { anketiranjem } \\
\text { medicinskih sester }\end{array}$ & $\begin{array}{l}300 \text { kritično } \\
\text { bolnih, } 44 \\
\text { medicinskih sester }\end{array}$ & $\begin{array}{l}\text { Ciljni vrednosti } \\
\text { glukoze v krvi }(70,4 \% \\
[s, 15,2 \%]) \text { je } \\
\text { pri računalniško } \\
\text { vodenem protokolu } \\
\text { ustrezalo več meritev } \\
\text { kot pri tradicionalno } \\
\text { vodenem protokolu } \\
(61,6 \%[s, 17,9 \%], Z= \\
-4,423, p<0,001) .\end{array}$ \\
\hline $\begin{array}{l}\text { Chant, et al., } \\
2012\end{array}$ & $\begin{array}{l}\text { Primerjati varnost } \\
\text { in učinkovitost } \\
\text { pri uporabi } \\
\text { nomograma in pri } \\
\text { strokovni presoji } \\
\text { medicinskih sester }\end{array}$ & $\begin{array}{l}\text { Prospektivna } \\
\text { randomizirana } \\
\text { raziskava }\end{array}$ & $\begin{array}{l}\text { Ocenjevanje } \\
\text { učinkovitosti } \\
\text { izbranih metod } \\
\text { (nomogram in } \\
\text { strokovna presoja } \\
\text { medicinskih sester) }\end{array}$ & $\begin{array}{l}34 \text { medicinskih } \\
\text { sester in } 97 \\
\text { izmerjenih } \\
\text { podatkov o } \\
\text { vrednosti glukoze } \\
\text { v krvi }\end{array}$ & $\begin{array}{l}\text { Strokovna presoja } \\
\text { medicinskih sester je } \\
\text { enako učinkovita kot } \\
\text { nomogram. }\end{array}$ \\
\hline $\begin{array}{l}\text { Van Herpe, et } \\
\text { al., } 2013\end{array}$ & $\begin{array}{l}\text { Primerjati } \\
\text { računalniški } \\
\text { protokol } \\
\text { LOGIC-C z } \\
\text { vodenjem s } \\
\text { strani izkušenih } \\
\text { medicinskih sester }\end{array}$ & $\begin{array}{l}\text { Primerjalna } \\
\text { randomizirana } \\
\text { konrolirana } \\
\text { raziskava }\end{array}$ & $\begin{array}{l}\text { Ocenjevanje indeksa } \\
\text { glikemičnega } \\
\text { nadzora }\end{array}$ & $\begin{array}{l}300 \text { kritično bolnih, } \\
\text { randomiziranih v } \\
151 \text { vodenih s strani } \\
\text { medicinskih sester } \\
\text { in } 149 \text { vodenih } \\
\text { po protokolu } \\
\text { LOGIC-C }\end{array}$ & $\begin{array}{l}\text { Vodenje po protokolu } \\
\text { LOGIC-C omogoča } \\
\text { boljšo učinkovitost } \\
\text { v primerjavi } \\
\text { z vodenjem s } \\
\text { strani izkušenih } \\
\text { medicinskih sester. }\end{array}$ \\
\hline $\begin{array}{l}\text { Dubois, et al., } \\
2017\end{array}$ & $\begin{array}{l}\text { Primerjati } \\
\text { računalniško } \\
\text { vodeni protokol } \\
\text { LOGIC z } \\
\text { vodenjem s strani } \\
\text { medicinskih sester }\end{array}$ & $\begin{array}{l}\text { Mednarodna } \\
\text { multicentrična } \\
\text { randomizirana } \\
\text { kontrolirana } \\
\text { raziskava }\end{array}$ & $\begin{array}{l}\text { Ugotavljanje } \\
\text { doseženih vrednosti } \\
\text { glukoze v krvi, } \\
\text { sekundarno tudi } \\
\text { ugotavljanje } \\
\text { prisotnosti } \\
\text { okužb, števila } \\
\text { bolniškooskrbnih dni, } \\
\text { kakovosti življenja, } \\
\text { smrtnosti ipd. }\end{array}$ & $\begin{array}{l}1550 \text { kritično } \\
\text { bolnih v kirurških } \\
\text { in internističnih } \\
\text { intenzivnih } \\
\text { terapijah }\end{array}$ & $\begin{array}{l}\text { Protokol LOGIC } \\
\text { izboljša kakovost } \\
\text { glikemičnega } \\
\text { nadzora, in sicer brez } \\
\text { nevarnosti za pojav } \\
\text { hipoglikemije. }\end{array}$ \\
\hline $\begin{array}{l}\text { Okabayashi, et } \\
\text { al., } 2013\end{array}$ & $\begin{array}{l}\text { Ugotoviti } \\
\text { značilnosti } \\
\text { uporabe } \\
\text { računalniškega } \\
\text { sistema STG-22 }\end{array}$ & $\begin{array}{l}\text { Eksperimentalna } \\
\text { raziskava }\end{array}$ & $\begin{array}{l}\text { Ocenjevanje } \\
\text { pojavnosti } \\
\text { hipoglikemij } \\
\text { in delovnih } \\
\text { obremenitev pri } \\
\text { medicinskih sestrah }\end{array}$ & $\begin{array}{l}50 \text { kritično bolnih } \\
\text { v enoti kirurške } \\
\text { terapije, vprašalnik } \\
\text { za medicinske } \\
\text { sestre }\end{array}$ & $\begin{array}{l}\text { Sistem STG-22 } \\
\text { prinaša tehnične } \\
\text { izboljšave, zmanjšata } \\
\text { se tudi pojavnost } \\
\text { hipoglikemij } \\
\text { in anskioznost } \\
\text { medicinskih sester. }\end{array}$ \\
\hline
\end{tabular}

Legenda / Legend: LOGIC-C - protokol vodenja vrednosti glukoze v krvi / blood glucose control protocol; LOGIC - protokol vodenja vrednosti glukoze $v \mathrm{krvi} /$ blood glucose control protocol; STG-22 - protokol vodenja vrednosti glukoze v krvi / blood glucose control protocol; \% - odstotek / percentage; s - standardni odklon / standard deviation; Z - standardna vrednost / standard value; p - statistična značilnost / statistical significance 
različnih protokolov za vodenje vrednosti glukoze $\mathrm{v}$ krvi: (1) računalniško podprt inzulinski protokol $\mathrm{z}$ neprekinjeno inzulinsko infuzijo za vzdrževanje glukoze v krvi med 100 in $130 \mathrm{mg} / \mathrm{dl}$ (tj. 5,6-7,2 mmol/l), (2) protokol Leuven $\mathrm{z}$ infuzijo inzulina za vzdrževanje glukoze v krvi med 80 in $110 \mathrm{mg} / \mathrm{dl}(4,4-6,1 \mathrm{mmol} / \mathrm{l})$ in (3) konvencionalno zdravljenje s subkutanim inzulinom, če vrednost glukoze znaša nad $150 \mathrm{mg} / \mathrm{dl}(>8,3 \mathrm{mmol} / \mathrm{l})$. Večina medicinskih sester je večjo primernost pripisala računalniško podprtemu protokolu. Medicinske sestre (58 \%) menijo, da je omenjeni protokol bolj uspešen tako $\mathrm{v}$ primerjavi s protokolom Leuven $(p<0,001)$ kot tudi v primerjavi s konvencionalnim zdravljenjem $(p=0,08)$. Prav tako tudi Dumont in Bourguignon (2012) navajata prednosti računalniško vodenega protokola za vodenje vrednosti glukoze $\mathrm{v}$ krvi v smislu doseganja ciljne vrednosti koncentracije glukoze $\mathrm{v}$ krvi in višjega zadovoljstva medicinskih sester. Navajata, da je bilo zadovoljstvo medicinskih sester, ki so pri svojem delu uporabljale pomoč računalnika, višje kot pri kontrolni skupini $(p<0,001)$. Prospektivna randomizirana raziskava, ki je bila izvedena pri kritično bolnih pacientih $\mathrm{v}$ pooperativnem nadzoru na osnovi 44 podatkov iz nomogramov in 51 podatkov na osnovi lastne strokovne presoje medicinskih sester, kjer se je koncentracija glukoze $\mathrm{v}$ krvi vzdrževala nad $8 \mathrm{mmol} / \mathrm{l}$, ugotavlja, da je strokovna presoja medicinskih sester enako učinkovita kot vodenje vrednosti glukoze v krvi po nomogramu (Chant, et al., 2012). Van Herpe in sodelavci (2013) na osnovi primerjalne randominizirane kontrolirane raziskave, kjer so primerjali učinkovitost vodenja vrednosti glukoze $\mathrm{v}$ krvi s strani medicinskih sester preko ročno vodenega protokola Leuven (Leuven paper-based protocol) in preko računalniško vodenega protokola LOGIC (LOGIC - Insulin software), ugotavljajo, da računalniško vodeni protokol zmanjša incidenco hipoglikemije. Glede na zagovarjanje boljšega in varnejšega nadzora koncentracije glukoze $\mathrm{v}$ krvi s pomočjo računalniških algoritmov za vodenje vrednosti glukoze v krvi s strani medicinskih sester so Dubois in sodelavci (2017) izvedli mednarodno multicentrično randomizirano raziskavo, kjer so primerjali vodenje koncentracije glukoze $\mathrm{v}$ krvi po algoritmu LOGIC in vodenje $\mathrm{s}$ strani usposobljenih medicinskih sester. Zaključujejo, da uporaba kontrolnega algoritma $\mathrm{v}$ primerjavi $\mathrm{z}$ vodenjem $\mathrm{s}$ strani medicinskih sester izboljšuje kakovost nadzora koncentracije glukoze v krvi brez povečanja nevarnosti hipoglikemij. Okabayashi in sodelavci (2013) na osnovi izvedene eksperimentalne raziskave, kjer so proučevali vpliv računalniško vodenega sistema STG-22 (Closed Loop Glycemic Control System) na pojavnost hipoglikemij in delovnih obremenitev medicinskih sester, podobno ugotavljajo, da omenjeni računalniško vodeni sistem prinaša tehnične izboljšave, zmanjšanje pojavnosti hipoglikemij in zmanjšanje anskioznosti pri medicinskih sestrah. Podrobnejši opisi identificiranih raziskav so prikazani v Tabeli 2.
Delovne obremenitve medicinskih sester pri različnih protokolih vodenja vrednosti glukoze $v$ krvi pri kritično bolnih pacientih

V okviru drugega tematskega področja (Tabela 3), kjer opisujemo delovne obremenitve medicinskih sester, izvedeni pregled literature prikaže časovne delovne obremenitve medicinskih sester $\mathrm{v}$ zvezi $\mathrm{z}$ izvajanjem protokolov za vodenje vrednosti glukoze v krvi. Malesker in sodelavci (2007) so izvedli tri raziskave: neodvisno opazovanje oz. zbiranje podatkov o trajanju priprav za pričetek aplikacije inzulinske mešanice; pregled pogostnosti odstopanj od protokola, zabeleženih v zdravstveni dokumentaciji, in anketiranje medicinskih sester o poznavanju protokola za vodenje vrednosti glukoze $\mathrm{v}$ krvi in o njihovem zadovoljstvu pri delu. Ugotovitve teh treh izvedenih raziskav so, da povprečni pretečeni čas za pričetek infundiranja $\mathrm{z}$ inzulinsko mešanico znaša 12,83 minute, pregled diagrama pa pokaže 734 odstopanj pri 75 kritično bolnih, pri čemer je $57 \%$ odstopanj povezanih z načrtovanim časom za merjenje vrednosti glukoze v krvi. Medicinske sestre (70 \%) navajajo, da je protokol vodenja vrednosti glukoze povečal njihovo delovno obremenitev. V prospektivni pilotni raziskavi (Gartemann, et al., 2012), ki je bila izvedena v Veliki Britaniji, so ocenjevali celokupno časovno obremenitev medicinskih sester $\mathrm{v}$ zvezi $\mathrm{z}$ vodenjem glukoze $\mathrm{v}$ krvi pri kritično bolnih pacientih s pomočjo protokolov. Izvedli so opazovanja s strani štirih neodvisnih raziskovalcev in semistrukturirane intervjuje medicinskih sester in ugotovili, da je povprečno trajanje vseh aktivnosti $\mathrm{v}$ zvezi z glikemičnim nadzorom trajalo povprečno 6,65 minut. Tako medicinske sestre za vodenje vrednosti glukoze v krvi pri kritično bolnih pacientih po protokolih porabijo $7 \%$ delovnega časa $\mathrm{v}$ okviru ene delovne izmene (Gartemann, et al., 2012). Isti avtorji menijo, da so aktivnosti zdravstvene nege $\mathrm{v}$ okviru vodenja vrednosti glukoze $\mathrm{v}$ krvi rutinske in monotone. Aragon (2006) v eksplorativni raziskavi ugotavlja, da vodenje glukoze $\mathrm{v}$ krvi s pomočjo protokolov medicinske sestre ocenjujejo kot potreben in pomemben diagnostično-terapevtski postopek znotraj celotne zdravstvene oskrbe kritično bolnih pacientov, obenem pa tudi ugotavlja, da je s tem povezano delo precejšnje. Povprečen čas, potreben za urno preverjanje vrednosti glukoze $\mathrm{v}$ krvi in prilagajanje odmerkov inzulinske mešanice, znaša 4,72 minute. Menijo, da so potrebne lažje in avtomatizirane oblike nadzora koncentracije glukoze v krvi. Za odvzemno mesto priporočajo arterijsko kanilo. $\mathrm{V}$ povezavi $\mathrm{z}$ manjšimi delovnimi obremenitvami medicinskih sester Evans in sodelavci (2012) na osnovi v virtualnem okolju izvedene eksperimentalne raziskave navajajo prednosti protokola STAR (Stochastic Targeted) (letega so primerjali s protokolom SPRINT (Specialized Relative Insulin and Nutrition Titration)). 
Tabela 3: Raziskave, vključene v pregled literature v okviru drugega tematskega področja - delovne obremenitve medicinskih sester pri različnih protokolih vodenja vrednosti glukoze $v$ krvi pri kritično bolnih pacientih

Table 3: The studies included in the literature review within the framework of the second thematic area - nurses' workload

\begin{tabular}{|c|c|c|c|c|c|}
\hline $\begin{array}{l}\text { Avtor in leto / } \\
\text { Author and } \\
\text { year }\end{array}$ & $\begin{array}{l}\text { Namen / } \\
\text { Aim }\end{array}$ & $\begin{array}{l}\text { Raziskovalni } \\
\text { dizajn / } \\
\text { Research } \\
\text { design } \\
\end{array}$ & $\begin{array}{l}\text { Zbiranje in analiza } \\
\text { podatkov / } \\
\text { Data collection } \\
\text { and analysis }\end{array}$ & $\begin{array}{l}\text { Lastnosti vzorca / } \\
\text { Sample } \\
\text { characteristics }\end{array}$ & $\begin{array}{l}\text { Ključne ugotovitve / } \\
\text { Key findings }\end{array}$ \\
\hline $\begin{array}{l}\text { Malesker, et al., } \\
2007\end{array}$ & $\begin{array}{l}\text { Oceniti } \\
\text { učinkovitost } \\
\text { protokolov v } \\
\text { intenzivnih } \\
\text { terapijah }\end{array}$ & $\begin{array}{l}\text { Mešani } \\
\text { raziskovalni } \\
\text { dizajn }\end{array}$ & $\begin{array}{l}\text { Opazovanje, } \\
\text { retrospektivna analiza } \\
\text { dokumentacije } \\
\text { kritično bolnih } \\
\text { in anketiranje } \\
\text { medicinskih sester }\end{array}$ & $\begin{array}{l}47 \text { medicinskih } \\
\text { sester, } 38 \text { kritično } \\
\text { bolnih pacientov }\end{array}$ & $\begin{array}{l}70 \% \text { medicinskih } \\
\text { sester je navedlo, da } \\
\text { protokoli povečajo } \\
\text { njihove delovne } \\
\text { obremenitve. }\end{array}$ \\
\hline $\begin{array}{l}\text { Gartemann, et } \\
\text { al., } 2012\end{array}$ & $\begin{array}{l}\text { Pridobiti podatke } \\
\text { o času, ki ga } \\
\text { medicinske sestre } \\
\text { namenijo za delo } \\
\text { po protokolih }\end{array}$ & $\begin{array}{l}\text { Prospektivna } \\
\text { pilotna raziskava }\end{array}$ & $\begin{array}{l}\text { Opazovanje, } \\
\text { semistrukturirani } \\
\text { intervjuji in } \\
\text { anketiranje } \\
\text { medicinskih sester }\end{array}$ & Brez podatka & $\begin{array}{l}\text { Za delo, ki ga zahteva } \\
\text { protokol, medicinske } \\
\text { sestre namenijo } 7 \% \\
\text { delovnega časa. }\end{array}$ \\
\hline Aragon, 2006 & $\begin{array}{l}\text { Oceniti delo } \\
\text { medicinskih } \\
\text { sester na } \\
\text { področju } \\
\text { protokolov }\end{array}$ & $\begin{array}{l}\text { Eksplorativna } \\
\text { raziskava }\end{array}$ & $\begin{array}{l}\text { Ocenjevanje ravni } \\
\text { glukoze v krvi in } \\
\text { uporabe protokolov }\end{array}$ & $\begin{array}{l}66 \text { medicinskih } \\
\text { sester iz različnih } \\
\text { enot intenzivne } \\
\text { terapije }\end{array}$ & $\begin{array}{l}\text { Medicinske sestre } \\
\text { navajajo, da je vodenje } \\
\text { glukoze v krvi } \\
\text { pomembno, vendar je } \\
\text { s tem povezana tudi } \\
\text { znatna količina dela v } \\
\text { zdravstveni negi. }\end{array}$ \\
\hline $\begin{array}{l}\text { Evans, et al., } \\
2012\end{array}$ & $\begin{array}{l}\text { Oceniti varnost, } \\
\text { učinkovitost } \\
\text { in delovne } \\
\text { obremenitve } \\
\text { medicinskih } \\
\text { sester }\end{array}$ & $\begin{array}{l}\text { Eksperimentalna } \\
\text { raziskava }\end{array}$ & $\begin{array}{l}\text { Ocenjevanje } \\
\text { varnosti, } \\
\text { učinkovitosti } \\
\text { in delovnih } \\
\text { obremenitev } \\
\text { protokola STAR } \\
\text { v primerjavi } \\
\text { s protokolom } \\
\text { SPRINT } \\
\end{array}$ & $\begin{array}{l}370 \text { kritično bolnih, } \\
\text { pri katerih so } \\
\text { medicinske sestre } \\
\text { izvajale aplikacijo } \\
\text { inzulinske mešanice } \\
\text { in intervencije v } \\
\text { zvezi s hranjenjem } \\
\text { na } 1-3 \text { ure }\end{array}$ & $\begin{array}{l}\text { Protokol STAR v } \\
\text { virtualnem okolju } \\
\text { omogoča strog } \\
\text { glikemični nadzor } \\
\text { in v primerjavi s } \\
\text { protokolom SPRINT } \\
30 \% \text { manjšo } \\
\text { klinično obremenitev } \\
\text { medicinskih sester. }\end{array}$ \\
\hline
\end{tabular}

Legenda / Legend: STAR - protokol vodenja vrednosti glukoze v krvi / blood glucose control protocol; SPRINT - protokol vodenja vrednosti glukoze $v$ krvi / blood glucose control protocol; \% - odstotek / percentage

Varnost različnih protokolov vodenja vrednosti glukoze v krvi pri kritično bolnih pacientih

$\mathrm{V}$ raziskavah, ki se nanašajo na varnost protokolov vodenja vrednosti glukoze $\mathrm{v}$ krvi pri kritično bolnih pacientih, so avtorji izvedenih raziskav ugotavljali znanje medicinskih sester o protokolih vodenja vrednosti glukoze v krvi (Hargraves, 2014), učinkovitost in varnost sistema za nadzor koncentracije glukoze v krvi (angl. Space Glucose System - SGC) (Amrein, et al., 2014), variabilnost vrednosti glukoze v krvi ter ocenjevanje varnosti splošnih protokolov vodenja vrednosti glukoze v krvi (Campion, et al., 2011; Khalaila, et al., 2011; Stoecklin, et al., 2016). Retrospektivna opisna raziskava (Hargraves, 2014), izvedena $s$ pomočjo vprašalnika o merjenju znanja medicinskih sester o protokolih vodenja vrednosti glukoze v krvi, ugotavlja povečanje znanja medicinskih sester po izvedenem izobraževanju. Sistem za nadzor koncentracije glukoze v krvi SGC je pripomoček za nadzor glikemije, ki združuje infuzijske črpalke $s$ pomočjo računalniškega algoritma. Amrein in sodelavci (2014) so izvedli dve primerjalni neeksperimentalni raziskavi $\mathrm{v}$ dveh intenzivnih enotah (Avstrija in Švica) in preverjali učinkovitost pri doseganju ciljnih vrednosti glukoze $\mathrm{v}$ krvi $(4,4-8,3 \mathrm{mmol} / \mathrm{l})$, povprečno koncentracijo glukoze $\mathrm{v}$ krvi in intervale vzorčenja ter varnost glede pojavnosti hipoglikemičnih epizod (vrednost glukoze v krvi $\leq 2,2 \mathrm{mmol} / \mathrm{l}$ ). Po njihovih ugotovitvah sistem SGC predstavlja varen in učinkovit pripomoček za uravnavanje ciljne vrednosti glukoze v krvi pri kritično bolnih pacientih. Campion in sodelavci (2011) na osnovi izvedene retrospektivne analize podatkov kritično bolnih in etnografske raziskave pri medicinskih sestrah, kjer so proučevali značilnosti in učinke odmerjanja inzulinske mešanice, ugotavljajo, da medicinske sestre upoštevajo količino priporočenega odmerka inzulinske mešanice, ne pa tudi trenda inzulinske rezistence. Stoecklin in sodelavci (2016) na osnovi analize 28.690 vzorcev glukoze v krvi, kjer so ocenjevali varnost splošnih protokolov vodenja vrednosti glukoze v krvi, navajajo, da standardizirani protokoli vodenja vrednosti glukoze v krvi izboljšajo varnost vzdrževanja glikemije pri kritično bolnih pacientih. Tudi Khalaila in sodelavci (2011) zaključujejo, da vodenje protokola za 
Tabela 4: Raziskave, vključene v pregled literature v okviru tretjega tematskega področja - varnost različnih protokolov vodenja vrednosti glukoze $v$ krvi pri kritično bolnih pacientih

Table 4: The studies included in the literature review within the framework of the third thematic area - safety of blood glucose control protocols

\begin{tabular}{|c|c|c|c|c|c|}
\hline $\begin{array}{l}\text { Avtor in leto / } \\
\text { Author and } \\
\text { year }\end{array}$ & $\begin{array}{l}\text { Namen / } \\
\text { Aim }\end{array}$ & $\begin{array}{l}\text { Raziskovalni } \\
\text { dizajn / } \\
\text { Research design }\end{array}$ & $\begin{array}{l}\text { Zbiranje in analiza } \\
\text { podatkov / } \\
\text { Data collection } \\
\text { and analysis }\end{array}$ & $\begin{array}{l}\text { Lastnosti vzorca / } \\
\text { Sample } \\
\text { characteristics }\end{array}$ & $\begin{array}{l}\text { Ključne ugotovitve / } \\
\text { Key findings }\end{array}$ \\
\hline $\begin{array}{l}\text { Hargraves, } \\
2014\end{array}$ & $\begin{array}{l}\text { Oceniti znanje } \\
\text { medicinskih } \\
\text { sester, zaposlenih } \\
\text { v kardiokirurški } \\
\text { intenzivni } \\
\text { terapiji pred in } \\
\text { po izvedenem } \\
\text { izobraževanju } \\
\text { s področja } \\
\text { protokolov }\end{array}$ & $\begin{array}{l}\text { Retrospektivna } \\
\text { opisna raziskava }\end{array}$ & $\begin{array}{l}\text { Lastno razvit } \\
\text { vprašalnik za } \\
\text { merjenje znanja } \\
\text { o nadziranju } \\
\text { vrednosti glukoze } \\
\text { v krvi }\end{array}$ & $\begin{array}{l}29 \text { medicinskih } \\
\text { sester, } 76 \text { kritično } \\
\text { bolnih (pregled } \\
\text { elektronskih } \\
\text { zdravstvenih } \\
\text { kartotek) } \\
\text { Podatki o } \\
\text { vrednostih } \\
\text { glukoze v krvi } \\
\text { (pred anestezijo in } \\
\text { drugi pooperativni } \\
\text { dan). }\end{array}$ & $\begin{array}{l}\text { Znanje medicinskih } \\
\text { sester o protokolih } \\
\text { se je po izvedenem } \\
\text { izobraževanju } \\
\text { statistično značilno } \\
\text { izboljšalo }(p<0,001) \text {. }\end{array}$ \\
\hline $\begin{array}{l}\text { Amrein, et al., } \\
2014\end{array}$ & $\begin{array}{l}\text { Raziskati } \\
\text { učinkovitost in } \\
\text { varnost sistema } \\
\text { SGC }\end{array}$ & $\begin{array}{l}\text { Neeksperimentalna } \\
\text { primerjalna } \\
\text { raziskava }\end{array}$ & $\begin{array}{l}\text { Vprašalnik za } \\
\text { medicinske sestre: } \\
\text { ocenjevanje } \\
\text { učinkovitosti glede } \\
\text { hitrosti doseganja } \\
\text { ciljne vrednosti } \\
\text { glukoze v krvi in } \\
\text { ocenjevanje varnosti } \\
\text { glede pojavnosti } \\
\text { hipoglikemije }\end{array}$ & $\begin{array}{l}40 \text { kritično } \\
\text { bolnih v dveh } \\
\text { intenzivnih } \\
\text { terapijah }\end{array}$ & $\begin{array}{l}\text { Sistem SGC je varen in } \\
\text { učinkovit. Želeni čas } \\
\text { za doseganje vrednosti } \\
\text { glukoze v krvi } 4,4-8,3 \\
\text { mmol/l je bil dosežen } \\
\text { pri } 88,3 \% \text { kritično } \\
\text { bolnih. }\end{array}$ \\
\hline $\begin{array}{l}\text { Campion, et } \\
\text { al., } 2011\end{array}$ & $\begin{array}{l}\text { Določiti } \\
\text { značilnosti } \\
\text { merjenja in učinke } \\
\text { pri vodenju } \\
\text { vrednosti glukoze } \\
\text { v krvi }\end{array}$ & $\begin{array}{l}\text { Mešani dizajn - } \\
\text { retrospektivna } \\
\text { analiza (kritično } \\
\text { bolni) in } \\
\text { etnografska } \\
\text { raziskava } \\
\text { (medicinske sestre) }\end{array}$ & $\begin{array}{l}\text { Ocenjevanje } \\
\text { variabilnosti } \\
\text { glukoze v krvi } \\
\text { in inzulinske } \\
\text { rezistence }\end{array}$ & $\begin{array}{l}25 \text { medicinskih } \\
\text { sester }\end{array}$ & $\begin{array}{l}\text { Medicinske sestre } \\
\text { upoštevajo količino } \\
\text { priporočenega } \\
\text { odmerka inzulina, ne } \\
\text { upoštevajo pa trenda } \\
\text { inzulinske rezistence. }\end{array}$ \\
\hline $\begin{array}{l}\text { Stoecklin, et } \\
\text { al., } 2016\end{array}$ & $\begin{array}{l}\text { Oceniti varnost } \\
\text { štirih protokolov }\end{array}$ & $\begin{array}{l}\text { 15-letna } \\
\text { retrospektivna } \\
\text { opisna raziskava }\end{array}$ & $\begin{array}{l}\text { Analiza podatkov o } \\
\text { presnovi glukoze } \mathrm{v} \\
\text { krvi in o lastnostih } \\
\text { kritično bolnih }\end{array}$ & $\begin{array}{l}229 \text { kritično } \\
\text { bolnih }\end{array}$ & $\begin{array}{l}\text { Standardizirani } \\
\text { protokoli izboljšajo } \\
\text { nadzor glikemije. }\end{array}$ \\
\hline $\begin{array}{l}\text { Khalaila, et } \\
\text { al., } 2011\end{array}$ & $\begin{array}{l}\text { Oceniti } \\
\text { učinkovitost in } \\
\text { varnost protokola, } \\
\text { ki ga vodijo } \\
\text { medicinske sestre }\end{array}$ & $\begin{array}{l}\text { Prospektivna } \\
\text { primerjalna } \\
\text { raziskava }\end{array}$ & $\begin{array}{l}\text { Ocenjevanje ravni } \\
\text { glukoze v krvi } \\
\text { in pojavnosti } \\
\text { hipoglikemije }\end{array}$ & $\begin{array}{l}153 \text { kritično } \\
\text { bolnih }\end{array}$ & $\begin{array}{l}\text { Vodenje protokola s } \\
\text { strani medicinskih } \\
\text { sester učinkovito } \\
\text { prispeva k } \\
\text { zmanjševanju } \\
\text { pojavnosti } \\
\text { hipoglikemij. }\end{array}$ \\
\hline
\end{tabular}

Legenda / Legend: SGC - sistem za nadzor koncentracije glukoze v krvi / space glucose system; \% - odstotek / percentage; $p$ - statistična značilnost / statistical significance; mmol/l - milimol na liter / milimoles per litre

uravnavanje glukoze v krvi s strani medicinskih sester prispeva $\mathrm{k}$ učinkovitosti in varnosti glede pojavnosti hipoglikemij pri kritično bolnih pacientih. Rezultate prikazuje Tabela 4.

\section{Diskusija}

Glede na namen raziskave ugotoviti prednosti in slabosti najbolj pogostih protokolov vodenja vrednosti glukoze v krvi pri kritično bolnih pacientih ugotavljamo, da imajo medicinske sestre pri vzdrževanju ustrezne ravni koncentracije glukoze $\mathrm{v}$ krvi pomembno vlogo. Zdravljenje kritično bolnih pacientov $\mathrm{v}$ enoti intenzivne terapije pogosto poteka $\mathrm{z}$ inzulinsko infuzijsko mešanico, kar od medicinskih sester zahteva večkratne meritve koncentracije glukoze $\mathrm{v}$ krvi in prilagajanje doze inzulina (Kim, et al., 2012). Pri kritično bolnih pacientih so kot najprimernejša oblika vzdrževanja ciljnih glikemičnih vrednosti uveljavljeni kontiunirani protokoli vodenja vrednosti glukoze v krvi (Kelly, 2014). Čeprav v zadnjem desetletju obstaja veliko polemik glede optimalne ravni glukoze v krvi pri kritično bolnih pacientih, obstajajo dokazi, da višje vrednosti glukoze vodijo do povečane umrljivosti, obolevnosti in podaljšane hospitalizacije (Marik \& Preiser, 2010; Nelson, 2011). 
Prve polemike so vzpodbudili že leta 2001 objavljeni izsledki raziskave Van den Bergha in sodelavcev (2001), da so kritično bolni pacienti, pri katerih so bili uporabljeni t. i. tesni nadzori glukoze, imeli boljše preživetje v primerjavi s pacienti, pri katerih protokoli za uravnavanje vrednosti glukoze $\mathrm{v}$ krvi niso bili uporabljeni (Preiser, et al., 2016). Kalfon in sodelavci (2014) na osnovi multicentrične randomizirane raziskave v 34 enotah intenzivnih terapij pri skupaj 2646 kritično bolnih navajajo, da vodenje vrednosti glukoze $\mathrm{v}$ krvi pri kritično bolnih pacientih $\mathrm{s}$ pomočjo računalniških protokolov ni bistveno vplivalo na njihovo smrtnost, toda $\mathrm{v}$ primerjavi $\mathrm{s}$ konvencionalnim nadzorom koncentracije glukoze $\mathrm{v}$ krvi je bilo povezano s pogostejšimi hudimi epizodami hipoglikemije. Lange (2010) preko ugotovitev klinične raziskave navaja, da urejenost koncentracije glukoze v krvi izboljša zdravstvene izide pri kritično bolnih pacientih s hiperglikemijo ali sladkorno boleznijo ter da $\mathrm{z}$ uporabo inzulina lahko doseže ciljne glikemične vrednosti.

$\mathrm{V}$ izvedeni raziskavi smo preverjali različne protokole vodenja vrednosti glukoze $\mathrm{v}$ krvi pri kritično bolnih. Več raziskav (Corrêa, et al., 2009; Okabayashi, et al., 2013; Van Herpe, et al., 2013) ugotavlja prednosti računalniško podprtih protokolov v smislu tehnoloških izboljšav, zmanjšanja delovnih obremenitev medicinskih sester in varnosti kritično bolnih pacientov, medtem ko Chant in sodelavci (2012) ugotavljajo pomen lastne strokovne presoje medicinskih sester in "ročno vodenih" protokolov. Gartemann in sodelavci (2012) navajajo, da meritve koncentracije glukoze $\mathrm{v}$ krvi po protokolih, ki jih izvajajo medicinske sestre, predstavljajo določeno časovno potrebo. $\mathrm{Ne}$ glede na način vodenja protokolov, ali so računalniško ali ročno vodeni, lahko poudarimo ugotovitve raziskav, da ima vsak protokol določene prednosti in slabosti.

Predvsem je treba izpostaviti, da morajo biti medicinske sestre za vodenje vrednosti glukoze v krvi, še posebno za doziranje inzulinske infuzijske mešanice, ustrezno strokovno izobražene in usposobljene. Medicinske sestre, ki skrbijo za uravnavanje vrednosti glukoze v krvi pri kritično bolnih, izvajajo integracijo ocenjevanja, spremljanja in izvajanja intervencij $\mathrm{v}$ zvezi $\mathrm{z}$ vdrževanjem ustrezne ravni glukoze $\mathrm{v}$ krvi. Kot navajata Ng in Curley (2012) so medicinske sestre ključnega pomena za uspešno vodenje protokolov uravnavanja vrednosti glukoze $\mathrm{v}$ krvi in da so pri tem lahko psihično obremenjene. Sauer in Van Horn (2009) navajata, da vodenje vrednosti glukoze v krvi pri kritično bolnih pacientih s pomočjo protokolov sodi med zahtevne in zapletene aktivnosti $\mathrm{v}$ zdravstveni negi, in sicer tudi za medicinske sestre, ki imajo več poklicnih izkušenj.

Vseeno pa se, kot navajajo Schultz in sodelavci (2010), pojavlja vprašanje o tem, kdo naj bi bil za vsakodnevno vodenje vrednosti glukoze $\mathrm{v}$ krvi pri kritično bolnih pacientih odgovoren. Na osnovi dveh randomiziranih kliničnih raziskav navajajo, da te protokole vsakodnevno izvajajo medicinske sestre, in sicer brez poseganja zdravnikov intenzivistov, saj le-ti ob kritično bolnem niso pogosto prisotni. $\mathrm{Ob}$ tem pa navajajo, da bi kljub dokazom, da vodenje vrednosti glukoze v krvi pri kritično bolnih s pomočjo protokolov v praksi predstavlja aktivnost medicinskih sester, lahko trdili tudi, da le-te nimajo zadostnih informacij za varno uporabo teh protokolov, še zlasti, kadar je nadzor koncentracije glukoze v krvi usmerjen $\mathrm{v}$ spodnje meje ciljnih glikemičnih vrednosti. Pomembno je tudi dejstvo, da se medicinske sestre lahko ob tem počutijo pravno nezaščitene.

Omejitve izvedene raziskave se najprej nanašajo na populacijo kritično bolnih pacientov, saj smo v analizo vključili raziskave, katerih različno velike vzorce so predstavljali kritično bolni pacienti, obravnavani $\mathrm{v}$ različnih tipih intenzivnih terapij. Nadalje za omejitev lahko štejemo tudi primerjanje raznolikih protokolov in primerjanje podatkov, pridobljenih $\mathrm{z}$ različnimi raziskovalnimi dizajni. $\mathrm{V}$ slovenskem prostoru (še) nimamo raziskav, ki bi prikazale vključenost medicinskih sester $\mathrm{v}$ delo, povezano s protokoli vodenja vrednosti glukoze v krvi pri kritično bolnih. Glede na rezultate tujih raziskav, ki navajajo pogostnost teh meritev, bi take raziskave bile priporočljive tudi pri nas, saj omogočajo prikaz delovnih obremenitev $\mathrm{v}$ zdravstveni negi in $\mathrm{s}$ tem povezano kakovost in varnost zdravstvene oskrbe kritično bolnih pacientov. Smiselno bi bilo raziskati znanje medicinskih sester o zagotavljanju ustrezne ravni koncentracije glukoze $\mathrm{v}$ krvi pri kritično bolnih s pomočjo protokolov, vključenost medicinskih sester $\mathrm{v}$ delo po protokolih ter kakovost obravnave kritično bolnih pacientov in njihovo varnost na področju zagotavljanja ustrezne ravni koncentracije glukoze $\mathrm{v}$ krvi.

\section{Zaključek}

Vodenje vrednosti glukoze $\mathrm{v}$ krvi pri kritično bolnih pacientih je pomemben diagnostično-terapevtski postopek, pri katerem imajo medicinske sestre pomembno vlogo. Pomen vključevanja medicinskih sester in njihove vloge pri uravnavanju vrednosti glukoze $\mathrm{v}$ krvi po protokolih potrjujejo številne raziskave, ki obravnavajo prednosti in slabosti posameznih protokolov, delovne obremenitve medicinskih sester pri teh protokolih ter varnost pacientov, ki jo ti protokoli zagotavljajo. Meritve koncentracije glukoze $\mathrm{v}$ krvi in prilagoditev inzulinske mešanice predstavlja zahtevno in odgovorno delo medicinskih sester $\mathrm{v}$ intenzivnih terapijah, pri čemer je treba upoštevati, da je poleg varnosti kritično bolnih pacientov pomembna tudi pravna zaščita medicinskih sester. 


\section{Nasprotje interesov / Conflict of interest}

Avtorica izjavlja, da ni nasprotja interesov. / The author declares that no conflicts of interest exist.

\section{Financiranje / Funding}

Raziskava ni bila finančno podprta. / The study received no funding.

\section{Etika raziskovanja / Ethical approval}

Glede na izbrano metodologijo raziskovanja za izvedbo raziskave dovoljenje ali soglasje komisije za etiko ni bilo potrebno. / No approval by the Ethics Committee was necessary to conduct the study due to the selected research methodology.

\section{Prispevek avtorjev / Author contributions}

Članek je nastal v okviru doktorskega študija na interdisciplinarnem študijskem programu Javno zdravje smer Biomedicina na Medicinski fakulteti Univerze v Ljubljani, in sicer pod mentorstvom izr. prof. dr. Brigite Skele Savič, znan. svet., pri predmetu $\mathrm{Na}$ dokazih podprto delo $\mathrm{v}$ zdravstveni negi in zdravstvu. / The article was written as a requirement of the interdisciplinary doctoral programme Public Health - Biomedicine at the Faculty of Medicine, University of Ljubljana, under the mentorship of Dr Brigita Skela Savič, Associate Professor, Research Counsellor, with the course Evidence-based practice in nursing and healthcare.

\section{Literatura}

Al-Tarifi, A., Abou-Shala, N., Tamim, H.M., Rishu, A.H. \& Arabi, Y.M., 2011. What is the optimal blood glucose target in critically ill patients: a nested cohort study. Annals of Thoracic Medicine, 6(4), pp. 207-211.

https://doi.org/10.4103/1817-1737.84774

PMid:21977065; PMCid:PMC3183637

Amrein, K., Kachel, N., Fries, H., Hovorka, R., Pieber, T.R., Plank, J., et al., 2014. Glucose control in intensive care: usability, efficacy and safety of Space Glucose Control in two medical European intensive care units. BMC Endocrine Disorders, 29(14), p. 62.

https://doi.org/10.1186/1472-6823-14-62

PMid:25074071; PMCid:PMC4118658

Aragon, D., 2006. Evaluation of nursing work effort and perceptions about blood glucose testing in tight glycemic control. American Journal of Critical Care, 15(4), pp. 370-377. PMid:16823014
Beliard, R., Muzykovsky, K., Vincent, W., Shan, B. \& Davanos, E., 2016. Perceptions, barriers, and knowledge of Inpatient Glycemic Control: a survey of health care workers. Journal of Pharmacy Practice, 29(4), pp. 348-354.

https://doi.org/10.1177/0897190014566309

PMid:25609663

Campion, T.R., May, A.K., Waitman, L.R., Ozdas, A., Lorenzi, M.N. \& Gadd, C.S., 2011. Characteristics and effects of nurse dosing over-rides on computer-based intensive insulin therapy protocol performance. Journal of the American Medical Informatics Association, 18(3), pp. 251-258.

https://doi.org/10.1136/amiajnl-2011-000129

PMid:21402737; PMCid:PMC3078667

Chang, S.Y., Sevransky, J. \& Martin, G.S., 2012. Protocols in the management of critical illness. Critical Care, 16, p. 306.

https://doi.org/10.1186/cc10578

PMid:22424130; PMCid:PMC3584719

Chant, C., Mustard, M., Thorpe, K.E. \& Friedrich, J.O., 2012. Nurse - vs Nomogram-Directed Glucose Control in a Cardiovascular Intensive Care Unit. American Journal of Critical Care, 21(4), pp. 270-278.

https://doi.org/10.4037/ajcc2012713

PMid: 22751370

Corrêa, T., Pereira de Almeida, F., Biasi Cavalcanti, A., Jose Pereira, A. \& Silva E., 2009. Evaluation of nursing perceptions about three insulin protocols for blood glucose control in critical care. Critical Care, 13(1), p. 122.

https://doi.org/10.1186/cc7286

PMCid:PMC4084008

Cronin, P., Ryan, F. \& Coughlan, M., 2008. Undertaking a literature review: a step by step approach. British Journal of Nursing, 17(1), pp. 38-43.

https://doi.org/10.12968/bjon.2008.17.1.28059

PMid:18399395

Dharmalingam, M., 2016. Glycemic control in Intensive Care Unit. Indian Journal of Endocrinology and Metabolism, 20(4), pp. 415-417.

https://doi.org/10.4103/2230-8210.183459

PMid:27366704; PMCid:PMC4911827

Dubois, J., Van Herpe, T., van Hooijdonk, R.T., Wouters, R., Coart, D., Wouters, P., et al., 2017. Software-guided versus nurse-directed blood glucose control in critically ill patients: the LOGIC-2 multicenter randomized controlled clinical trial. Critical Care, 21(1), pp. 212.

https://doi.org/10.1186/s13054-017-1799-6

PMid:28806982; PMCid:PMC 5557320 
DuBose, J.J., Nomoto, S., Higa, L., Paolim, R., Teixeira, P.G., Inaba, K., et al., 2009. Nursing involvement improves compliance with tight blood glucose control in the trauma ICU: a prospective observational study. Intensive and Critical Care Nursing, 25(2), pp. 101-107.

https://doi.org/10.1016/j.iccn.2008.07.004

PMid:19135371

Dumont, C. \& Bourguignon, C., 2012. Effect of a computerized insulin dose calculator on the Process of Glycemic Control. American Journal of Critical Care, 21(2), pp. 106-115.

https://doi.org/10.4037/ajcc2012956

PMid:22381987

Evans, A., Le Compte, A., Tan, C.S., Ward, L., Steel, J., Pretty, C.G., et al., 2012. Stochastic targeted (STAR) glycemic control: design, safety, and performance. Journal of Diabetes Science and Technology, 6(1), pp. 102-115.

https://doi.org/10.1177/193229681200600113

PMid:22401328; PMCid:PMC3320827

Farrokhi, F., Smiley, D. \& Umpierrez, G.E., 2011. Glycemic control in non-diabetic critically ill patients. Best practice \& Research. Clinical Endocrinology \& Metabolism, 25(5), pp. 813-824.

https://doi.org/10.1016/j.beem.2011.05.004

PMid:21925080; PMCid:PMC3718463

Gardner, A.J., 2014. The benefits of tight glycemic control in critical illness: sweeter than assumed? Indian Journal of Critical Care Medicine, 18(12), pp. 807-813. https://doi.org/10.4103/0972-5229.146315

PMid:25538415; PMCid:PMC4271280

Gartemann, J., Caffrey, E., Hadker, N., Crean, S., Creed, G.M. \& Rausch, C., 2012. Nurse workload in implementing a tight glycaemic control protocol in a UK hospital: a pilot time-inmotion study. Nursing in Critical Care, 17(6), pp. 279-284.

https://doi.org/10.1111/j.1478-5153.2012.00506.x

PMid:23061617

Hargraves, J.D., 2014. Glycemic Control in cardiac surgery: implementing an evidence: based insulin infusion protocol. American Journal of Critical Care, 23(3), pp. 250-258.

https://doi.org/10.4037/ajcc2014236

PMid:24786814

Holzinger, U., Feldbacher, M., Bachlechner, A., Kitzberger, R., Fuhrmann, V. \& Madl, C., 2008. Improvement of glucose control in the intensive care unit: an interdisciplinary collaboration study. American Journal of Critical Care, 17(2), pp. 150-156. PMid:18310653

Hsu, C.W., 2012. Glycemic control in critically ill patients. World Journal of Critical Care Medicine, 1(1), pp. 31-39. https://doi.org/10.5492/wjccm.v1.i1.31 PMid:24701399; PMCid:PMC3956063
Kalfon, P., Giraudeau, B., Ichai, C., Guerrini, A., Brechot, N., Cinotti, R., et al., 2014. Tight computerized versus conventional glucose control in the ICU: a randomized controlled trial. Intensive Care Medicine, 40(2), pp. 171-181.

https://doi.org/10.1007/s00134-013-3189-0

PMid:24420499

Khalaila, R., Libersky, E., Catz, D., Pomerantsev, E., Bayya, A., Linton, D.M., et al., 2011. Nurse-led implementation of a safe and effective intravenous insulin protocol in a medical intensive care unit. Critical Care Nurse, 31(6), pp. 27-35.

https://doi.org/10.4037/ccn2011934

PMid:22135329

Kelly, J.L., 2014. Continuous insulin infusion: when, where, and how. Diabetes Spectrum, 27(3), pp. 218-223.

https://doi.org/10.2337/diaspect.27.3.218

PMid:26246783; PMCid:PMC4523736

Kim, S., Rushakoff, R.J., Sullivan, M. \& Windham, H., 2012. Hyperglycemia control of the nil per os patient in the intensive care unit: introduction of a simple subcutaneous insulin algorithm. Journal of diabetes science and technology, 6(6), pp. 1413-1419.

https://doi.org/10.1177/193229681200600622

PMid:23294788; PMCid:PMC3570883

Kopecky, P., Mraz, M., Blaha, J., Lindner, J., Svacina, Š., Hovorka, R., et al., 2013. The use of continuous glucose monitoring combined with computer-based eMPC algorithm for tight glucose control incardiosurgical ICU. Biomed Research International, 2013, art. ID 186439.

https://doi.org/10.1155/2013/186439

PMid:23555075; PMCid:PMC3595106

Krinsley, J.S., 2015. Glycemic control in the critically ill: what have we learned since NICE-SUGAR. Hospital Practice, 43(3), pp. 191-197.

https://doi.org/10.1080/21548331.2015.1066227

PMid:26224425

Lange, V.Z., 2010. Successful management of in-hospital hyperglycemia: the pivotal role of nurses in facilitating effective insulin use. Medsurgery Nursing - official Journal of the Accademy of Medical Surgical Nursing, 19(6), pp. 323-328.

Malesker, M.A., Foral, P.A., McPhillips, A.C., Christensen, K.J., Chang, J.A. \& Hilleman D. E., 2007. An efficiency evaluation of protocols for Tight Glycemic Control in Intensive Care Units. American Journal of Critical Care, 16(6), pp. 589-598. PMid:17962503

Marik, P.E.\& Preiser, J.C., 2010. Toward understanding tight glycemic control in the ICU: a systematic review and metaanalysis. CHEST Journal,137(3), pp. 544-551.

https://doi.org/10.1378/chest.09-1737

PMid:20018803 
Nelson, M., 2011. Impact of a nurse managed hyperglycemic intensive insulin protocol on glucose control: Master's thesis. Indiana: Ball state of University, School of Nursing, pp. 4-5.

Ng, L.S. \& Curley, M.A., 2012. "One more thing to think about..." Cognitive burden experienced by intensive care unit nurses when implementing a tight glucose control protocol. Journal of diabetes science and technology, 6(1), pp. 58-64. https://doi.org/10.1177/193229681200600108

PMid:22401323; PMCid:PMC3320822

Okabayashi, T., Kozuki, A., Sumiyoshi, T. \& Shima, Y., 2013. Technical challenges and clinical outcomes of using a closedloop Glycemic Control System in the hospital. Journal of Diabetes Science Technology. 7(1), pp. 238-246.

https://doi.org/10.1177/193229681300700129

PMid:23439182; PMCid:PMC3692238

The Nice Sugar Investigators, 2012. Hypoglycemia and risk of death in critically ill patients. The New England Journal of Medicine, 367, pp. 1108-1118.

https://doi.org/10.1056/NEJMoa1204942

PMid:22992074

Polit, D.F. \& Beck, C.T., 2008. Nursing research: generating and assessing evidence for nursing practice. 8 th ed. Lippincott Williams \& Wilkins, p. 32.

Preiser, J.C., Chase, J.G., Hovorka, R., Jeffrey, I., Joseph, J.I., Krinsley, J.S., et al., 2016. Glucose control in the ICU. Journal of Diabetes Science and Technology, 10(6). https://doi.org/10.1177/1932296816648713

PMid:27170632; PMCid:PMC5094326

Sauer, P. \& Van Horn, E.R., 2009. Impact of intravenous insulin protocols on hypoglycemia, patient safety, and nursing workload. Dimensions of Critical Care Nursing, 28, pp. 95-101. https://doi.org/10.1097/DCC.0b013e31819af06d PMid:19387267
Schultz, M.J., Harmsen, R.E. \& Spronk, P.E., 2010. Clinical review: strict or loose glycemic control in critically ill patients - implementing best available evidence from randomized controlled trials. Critical Care, 14(3), p. 223.

https://doi.org/10.1186/cc8966

PMid:20550725; PMCid:PMC2911685

Schultz, M.J., Harmsen, R.E., Korevaar, J.C., Abu-Hanna, A., Van Braam Houckgeest, F., Van Der Sluijs, J.P., et al., 2012. Adoption and implementation of the original strict glycemic control guideline is feasible and safe in adult critically ill patients. Minerva Anestesiologica, 78(9), pp. 982-995.

PMid:22531562

Stoecklin, P., Delodder, F., Pantet, O. \& Berger, M.M., 2016. Moderate glycemic control safe in critically ill adult burn patients: a 15 year cohort study. Burns, 42(1), pp. 63-70. https://doi.org/10.1016/j.burns.2015.10.025

PMid:26691869

Van den Berghe, G., Wouters, P., Weekers, F., Verwaest, C., Bruyninckx, F., Schetz, M., et al., 2001. Intensive insulin therapy in critically ill patients. The New Journal of Medicine, 345(19), pp. 1359-1367. https://doi.org/10.1056/NEJMoa011300

PMid:11794168

Van Herpe, T., Mesotten, D., Wouters, P.J., Herbots, J., Voets, E., Buyens, J., et al., 2013. LOGIC-insulin algorithm-guided versus nurse-directed blood glucose control during critical illness: the LOGIC-1 single-center, randomized, controlled clinical trial. Diabetes Care. 36(2), pp. 188-194.

https://doi.org/10.2337/dc12-0584 PMid:22961576; PMCid:PMC3554274

Welch, V., Petticrew, M., Tugwell, P., Moher, D., O'Neill, J., Waters, E., et al., 2012. PRISMA-Equity 2012 Extension: reporting Guidelines for systematic reviews with a focus on health equity. Public Library of Science Medicine, 9(10), art. ID e1001333. https://doi.org/10.1371/journal.pmed.1001333

Citirajte kot / Cite as:

Kalender Smajlović, S., 2018. Prednosti in slabosti različnih protokolov vodenja vrednosti glukoze v krvi pri kritično bolnih pacientih: pregled literature. Obzornik zdravstvene nege, 52(1), pp. 45-56. https://doi.org/10.14528/snr.2018.52.1.181 